\title{
Review manuscript: Mechanisms of platelet activation by the pneumococcus and the role of platelets in community-acquired pneumonia
}

Ronald Anderson ${ }^{1, *}$ and Charles Feldman ${ }^{2}$

${ }^{1}$ Department of Immunology and Institute for Cellular and Molecular Medicine, Faculty of Health Sciences, University of Pretoria, Pretoria, South Africa

${ }^{2}$ Division of Pulmonology, Department of Internal Medicine, Charlotte Maxeke Johannesburg Academic Hospital and Faculty of Health Sciences, University of the Witwatersrand, Johannesburg, South Africa

Running title: Platelet activation by the pneumococcus

${ }^{*}$ Corresponding author: $\mathrm{R}$. Anderson
Department of Immunology
University of Pretoria
PO Box 667
Pretoria 0001
South Africa
+27-12-319-2425
Telephone: $\quad+27-12-323-0732$
Telefax: $\quad$ E-mail address: ronald.anderson@up.ac.za

$\underline{\text { Highlights }}$

- The pneumococcus promotes platelet activation.

- This is achieved by various mechanisms involving bacterial adhesins, pneumolysin and possibly $\mathrm{H}_{2} \mathrm{O}_{2}$.

- Pneumococcal and all-cause CAP are associated with alterations in blood platelet counts, particularly thrombocytopenia.

- Altered platelet counts in CAP are predictive of a poor outcome

- Measurement of systemic biomarkers of platelet activation in CAP may have predictive potential. 


\section{Summary}

There is increasing recognition of the involvement of platelets in orchestrating inflammatory responses, driving the activation of neutrophils, monocytes and vascular endothelium, which, if poorly controlled, may lead to microvascular dysfunction. Importantly, hyperreactivity of platelets has been implicated in the pathogenesis of myocardial injury and the associated particularly high prevalence of acute cardiovascular events in patients with severe community-acquired pneumonia (CAP), of which Streptococcus pneumoniae (pneumococcus) is the most commonly encountered aetiologic agent. In this context, it is noteworthy that a number of studies has documented various mechanisms by which the pneumococcus may directly promote platelet aggregation and activation. The major contributors to platelet activation include several different types of pneumococcal adhesin, the poreforming toxin, pneumolysin, and possibly pathogen-derived hydrogen peroxide, which collectively represent a major focus of the current review. This is followed by an overview of the limited experimental studies together with a larger series of clinical studies mainly focused on all-cause CAP, which have provided evidence in support of associations between alterations in circulating platelet counts, most commonly thrombocytopenia, and a poor clinical outcome. The final section of the review covers, albeit briefly, systemic biomarkers of platelet activation which may have prognostic potential.

Keywords: Adhesins; Hydrogen peroxide; Platelets; Platelet-activating factor; Pneumococcus; Pneumolysin; Streptococcus pneumoniae; Thrombocytopenia; Thrombocytosis; Toll-like receptors. 


\section{Introduction}

Lower respiratory tract infections remain a major contributor to the burden of disease in the world, being the leading communicable disease cause of death in the developing world and the fifth most common cause of death in developed countries $[1,2]$. In South Africa, for example, the entity of "Influenza and Pneumonia" is the second most common natural cause of death in all age groups [3]. In the United Kingdom, as another example, lower respiratory tract infections account for $5-10 \%$ of deaths, depending upon which definitions are used [4]. Furthermore, communityacquired pneumonia (CAP) is the most common infection causing patients to present to hospital in the western world and while the mortality rate in patients treated as outpatients is relatively low $(<1 \%)$, some $5-15 \%$ of inpatients will die within 30 -days of presentation [5].

While there are regional variations in the aetiology of CAP in the world [6], most studies indicate that Streptococcus pneumoniae (the pneumococcus) is the most common cause [7]. This is independent of the severity of the infection and the pneumococcus has been documented to be the predominant pathogen in cases mild enough to be treated on an outpatient basis, as well as in hospitalised cases, and even among cases requiring intensive care unit (ICU) admission [7]. The reason that the pneumococcus is such a common pathogen relates to the myriad of risk factors for invasive pneumococcal infections that exist in patients throughout the world [8]. Among these risk factors, ageing is prominent and the mechanisms underlying this increased risk are multifactorial [9]. Even in the elderly, many studies on aetiology confirm that the most common cause of CAP is the pneumococcus [9]. CAP in the elderly has considerable medical impact and the elderly are not only at greater risk of infection, but have higher rates of hospitalisation and considerably higher morbidity and mortality [9]. Furthermore, since it is well recognised that populations in most countries in the world are ageing [10], it is expected that the medical and economic impact of CAP, and particularly pneumococcal CAP, is likely to increase considerably in the coming decades [9].

Recent studies have indicated that a considerable number of deaths from CAP appear to be related to cardiovascular events that occur during the course of the infection [5] and while the mechanisms of these cardiovascular events appear to 
be multifactorial and involve the pathogen and pathogen-related virulence factors [5], there also appears to be an important emerging role for platelet activation underlying, at least some, of these events [11]. In this context, the current review is focused primarily on: i) the mechanisms, both established and proposed, by which the pneumococcus, the major cause of CAP, promotes platelet aggregation and activation; and ii) to link these findings with studies, mostly clinical, which have probed associations between alterations in the numbers and activities of circulating platelets with morbidity and mortality predominantly in patients with all-cause CAP, due to the paucity of reports in pneumococcal CAP. These topics are followed by a brief overview of systemic biomarkers of platelet activation with predictive potential in CAP.

\section{Platelet aggregation mediated by interaction of the pneumococcus with human platelets}

An early study reported by Guckian in 1975 appears to have been one of the first to document activation of platelets by the pneumococcus in vitro [12]. In this study, the author investigated the effects of addition of serotype 1 of the pneumococcus to whole blood, or to platelet-rich, or platelet-poor plasma, on both clot formation and platelet aggregation measured visually and microscopically respectively [12]. Addition of the pneumococcus at final concentrations ranging from $10^{6}-10^{8}$ organisms $/ \mathrm{mL}$ to all three matrices caused marked shortening of clotting times, as well as platelet aggregation [12]. Characteristics of these pro-coagulant/prothrombotic activities of intact pneumococci included: i) lack of involvement of complement activation; ii) attenuation by treatment of platelet suspensions with cellpermeable dibutyryl-3',5'-cyclic adenosine monophosphate (dcAMP), probably as a consequence of cAMP-mediated accelerated re-sequestration of mobilised $\mathrm{Ca}^{2+}$ into platelet storage organelles [13, 14]; iii) partial mimicking by purified capsular polysaccharide, which promoted clot formation, but not platelet aggregation, a finding which was confirmed in later studies documenting that aggregation of platelets in whole blood was mediated predominantly by non-encapsulated pneumococci, consistent with the requirement for exposure of bacterial cell wall adhesins $[15,16]$; and iv) the occurrence of intravascular coagulation in an experimental animal model of pneumococcal bacteraemia [12]. 
These early investigators, possibly restricted by the technologies available at that time, did not, however, report on either the presence of pneumococci in platelet aggregates, or on the mechanisms of platelet aggregation and clot formation [12]. More recent studies have, however, clearly demonstrated that the pneumococcus not only binds to, and activates platelets in vitro, but also causes systemic activation of these cells in the few published studies based on animal models of experimental infection and possibly in humans with invasive pneumococcal disease (IPD). Several of these mechanisms of platelet activation are not, however, unique to the pneumococcus and are applicable to other types of bacterial pathogen [17].

\section{Mechanisms which promote the pro-adhesive interactions of the pneumococcus with human platelets}

These involve not only adhesion of the pneumococcus to receptors expressed constitutively by quiescent platelets, some of which undergo upregulation of expression following cell activation, but also adhesion to granule-derived factors released by activated platelets. The former include the platelet-activating factor receptor (PAFR), the immunoglobulin G Fc receptor, FcyRIIA, and possibly Toll-like receptors (TLRs). Those in the second category involve activation of the integrin glycoprotein (GP) $\|\mathrm{b} /\| \mathrm{lla}(\mathrm{a} \mid \mathrm{lb} / \beta-3)$, as well as release of the granule proteins, platelet factor-4 and thrombospondin-1. An additional mechanism involves pneumococcal adhesion mediated by the interaction of bacteriophage-encoded surface adhesins with poorly characterised receptors on human platelets.

\section{PAFR-mediated}

It is well recognised that colonisation of the respiratory tract by the pneumococcus involves, amongst other pro-adhesive mechanisms, binding of the pathogen to the PAFR expressed on respiratory epithelium $[15,18]$. This interaction is mediated via the binding of predominantly sub-capsular lipoteichoic acid-associated phosphorylcholine to the PAFR, promoting attachment to, but not activation of the receptor in several different types of eukaryotic cells $[18,19]$. On the other hand, somewhat surprisingly, the possible involvement of pneumococcal phosphorylcholine/PAFR interactions in promoting platelet aggregation appears to be largely unexplored. Nonetheless, some support, albeit indirect, for the existence 
of this mechanism can be derived from observations with the bovine respiratory pathogen, Histophilus somni [20]. In this context, addition of phosphorylcholineexpressing strains of $H$. somni to bovine platelets resulted in the formation of platelet/bacteria aggregates, which was attenuated by inclusion of the PAFR antagonist, WEB2170, consistent with bacterial cross-linking of platelets via the PAFR [20].

\section{Fcy-receptor IIA (FcYRIIA)-mediated}

Human platelets have also been reported to express FcyRIIA [21, 22], but not any other type of Fcy receptor [17]. FcyRIIA is the only immunoglobulin receptor which interacts with antibodies of the lgG2 subclass, thereby mediating protective immune responses directed against pneumococcal capsular polysaccharides [23], while having lower affinities for the IgG1, IgG3 and IgG4 subclasses [24]. Platelet aggregation induced by Escherichia coli has been reported to be dependent on FcyRIIA, potentiated by activation of GPIIb/IIla and mobilisation of thromboxane $A_{2}$ $\left(\mathrm{TxA}_{2}\right)$ [25]. Although, to our knowledge, this pro-adhesive mechanism has not yet been described for the pneumococcus, it does seem probable that this bacterial pathogen in its encapsulated state may also promote platelet aggregation and activation via IgG2/FcyRIIA-dependent mechanisms, particularly at high bacterial densities, possibly potentiated by complement activation [26]. This contention is supported by observations that in Gram-positive bacteria belonging to the Staphylococcus and Streptococcus genera, including the pneumococcus, platelet aggregation and activation is potentiated by an FcyRIIA-dependent, autocrine mechanism which involves interaction of anionic surface components of the bacteria with the pro-coagulant, antimicrobial CXC chemokine, platelet factor-4, released during mobilisation of platelet $\alpha$-granules [27]. In this setting, bacteria to which platelet factor- 4 has bound are recognised, in turn, by pathogen-specific $\lg G$, to form a complex which binds to the platelet FcyRIIA, resulting in activation of GPIIb/IIla and fibrinogen binding, promoting platelet aggregation and activation [27, 28].

FcyRIIA may also contribute to platelet activation via complement-dependent mechanisms. This contention is based on observations that administration of human anti-pneumococcal antibodies of the $\lg G 1$ and $\lg G 2$ subclasses to mice has been reported to mediate passive protection against experimental infection with the 
pneumococcus, which was dependent on complement activation by both subclasses [29]. In this context, it is noteworthy that human platelets express several types of receptor which are interactive with complement cleavage/activation products. These include $\mathrm{gC} 1 \mathrm{q}$ receptors, which interact with pathogen-bound $\mathrm{C} 1 \mathrm{q}$, as well as receptors for complement-derived $\mathrm{C} 3 \mathrm{a}$ and $\mathrm{C} 5 \mathrm{a}$, with activation of all three receptor types resulting in platelet aggregation [30, 31].

\section{Thrombin-GPIIb/Illa-fibrin-thrombospondin-1-mediated}

Thrombin-mediated activation of platelets and simultaneous cleavage of fibrinogen has been reported to induce aggregate formation between human platelets and pneumococci, which was dependent on the formation of soluble fibrin and release of thrombospondin-1 (TS1) from activated platelets [32]. Although the exact mechanism of aggregate formation was not established, it may involve the binding of the pneumococcal adhesins, PavB and PspC, to the TS1 component of the GPIlb/IIlafibrin-TS1 complex [33-35]. A similar mechanism of platelet activation has also been described for Staphylococcus aureus [36], which also promotes activation of these cells via interaction with the platelet membrane glycoprotein, GPIb [17].

\section{Toll-like receptor (TLR)-mediated}

Of the currently documented 13 mammalian TLRs, 10 of which have been described in humans, human platelets express TLRs 1, 2, 3, 4, 6,7 and 9 [31], with TLR2 and TLR4 having been reported to mediate aggregation and activation of human platelets [37-39]. In the case of the pneumococcus, TLR2 expressed on human platelets, via its interactions with pneumococcal cell wall lipoteichoic acid and peptidoglycan, has been reported to mediate capsule-independent formation of bacteria:platelet aggregates following the addition of several different strains of the bacterial pathogen to human whole blood [40]. These TLR2-mediated pro-adhesive interactions have been reported to promote activation of GPIIb/IIla and mobilisation of dense granules [40]. More recently, other investigators have confirmed that addition of several non-encapsulated strains of the pneumococcus, but not their encapsulated counterparts, to both human and murine whole blood in vitro resulted in homotypic platelet aggregation, as well as platelet:leukocyte heterotypic aggregation. In this study, however, bacteria:platelet aggregate formation was not abrogated by inclusion of TLR blocking antibodies, neither was it mimicked by known 
agonists of TLRs [16]. In addition, the authors failed to eliminate pneumococcusmediated platelet aggregation when using a series of platelet single ( $T / r 2^{-/-}, \mathrm{Tlr}^{-{ }^{-}}$, TIr9 ${ }^{-/}$) TLR gene knockout mutants, as well as with a dual ( $\left./ 12^{-} / 4^{-}\right)$knockout and a

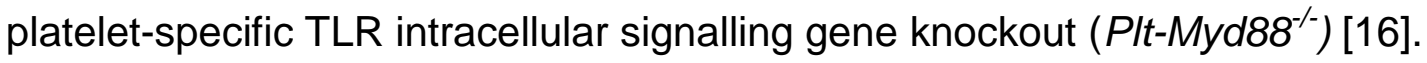

These latter observations appear to challenge the involvement of platelet TLR2 individually and in association with TLR4 on platelet aggregation and activation mediated by the pneumococcus, but apparently not in the case of other types of bacterial pathogen. This may be attributable to partial concealment of TLR ligands on the pneumococcal surface, as well as to the reportedly lower expression levels of TLR2 and TLR4 on the platelet outer membrane relative to the cytosol, possibly reducing the efficacy of platelet activation [41]. In this context, observations describing the interplay between various types of TLR in mediating platelet activation, as well as differential utilisation of intracellular signalling mechanisms by TLRs coupled to selective mediator release is noteworthy $[42,43]$.

\section{Platelet aggregation mediated by the bacteriophage adhesins, PbIA and PbIB}

Several earlier reports focused on viridans group streptococci described the involvement of the proteins PbIA and PbIB in promoting adherence of Streptococcus mitis to human platelets, an event which has been implicated in the pathogenesis of infective endocarditis $[44,45]$. Interestingly, however, neither of these proteins was encoded by the bacterial genome, but rather by the genome of the temperate bacteriophage, SM1, a member of the siphoviridae family [45, 46]. These phage proteins, of which PblB is most prominent with respect to mediation of platelet aggregation, apparently bear no structural similarity to recognised streptococcal adhesins, and appear to function as phage tail fibre proteins [46, 47]. In the case of S. mitis, expression of PbIA and PbIB on the bacterial surface is dependent on the activities of the bacteriophage lytic enzymes, holin and lysine, which hydrolyse the bacterial cell wall during the final stages of the lytic cycle [45]. Thereafter, PbIA and PbIB appear to attach to the choline moieties of bacterial cell wall lipoteichoic acid of viable organisms, enabling attachment to platelets, apparently via interaction with a2-8-linked sialic acid residues on platelet membrane gangliosides [45, 48]. 
More recently, a highly virulent clinical strain (NTUH-P15) of the pneumococcus belonging to serotype 14 , sequence type (ST) 46 , the prevalent clone of the pathogen causing pneumonia in children in Taiwan, was found, according to microarray analysis, to have a high level of expression of the gene encoding PbIB relative to that of control strains [49]. The authors observed that selective knockout of the pb/B gene attenuated the attachment of strain NTUH-P15 of the pathogen to human platelets, as well as to human airway epithelial (A549) and human larynx carcinoma (Hep-2) cell lines, which, in all cases, was restored by pb/B gene complementation. PbIB-mediated adhesion appeared to be dependent on a "galactose-binding, domain-like region" of the phage protein, which was also found to promote bacterial persistence in the nasopharynx and lungs in a murine model of experimental colonisation of the airways by NTUH-P15 [49]. Of 77 invasive pneumococcal isolates causing pneumonia, the prevalence of $p b / B$ gene-expressing strains of the pneumococcus among serotypes 14 ST46 and 6B ST76 (first and second most common respectively) was $25 / 25$ (100\%) compared to16/52 (31\%, $P<0.001)$ of the other strains not belonging to either of these genotypes [49].

In a very recently reported clinical study, pneumococcal genome-wide association studies performed on 349 hospitalised patients with proven pneumococcal bacteraemia demonstrated expression of the $p b / B$ gene in $48 \%$ of clinical isolates of the pathogen [50]. The authors of this study observed a strong statistical correlation $(P<0.00034)$ between expression of the $p b / B$ gene by isolates of the pneumococcus and 30-day mortality, with the presence of $p b / B$ being identified as an independent risk factor for 30-day mortality (OR=3.4; 95\% Cl, $1.2-$ 9.5) [50]. In addition, the authors also noted that exposure of 4 different clinical isolates of the pneumococcus to sub-lethal concentrations of fluoroquinolone antibiotics for 2 hours, but not the beta-lactam antibiotic, penicillin G, induced the expression of $p b / B$, the clinical significance of which remains to be established [50]. They also observed that addition of a wild type strain of the pneumococcus, but not a paired pblB gene knockout strain, to whole blood resulted in platelet activation measured according to increased expression of platelet P-selectin, activation of GPIIb/IIla and its binding to fibrinogen, as well as the formation of platelet:monocyte aggregates, none of which was affected by inclusion of either fluoroquinolones or penicillin $\mathrm{G}[50]$. 


\section{Mechanisms by which pneumococcus-derived factors promote platelet activation by receptor-independent mechanisms}

Additional mechanisms of pneumococcus-mediated platelet activation which bypass membrane receptors are considered here. These are focused firstly on the pneumococcal cholesterol-binding, pore-forming toxin, pneumolysin (Ply), for which supporting evidence exists, and, secondly on the potential involvement of pathogenderived $\mathrm{H}_{2} \mathrm{O}_{2}$, which is seemingly unexplored.

\section{Pneumolysin (PLY)-mediated $\mathrm{Ca}^{2+}$-dependent platelet activation}

PLY is the major protein toxin of the pneumococcus, which is produced in its active form by almost all clinical isolates of the pathogen [51, 52]. The toxin, which has a molecular weight of $53 \mathrm{kDa}$, belongs to the family of microbial pore-forming toxins, which bind to the cholesterol moieties of eukaryotic cells, promoting lytic or sub-lytic pore formation dependent on concentration [51, 52]. While the cytotoxic and proinflammatory effects of PLY on cells of the innate immune system, as well as structural cells, are well recognised, it is only fairly recently that the plateletactivating/pro-inflammatory/pro-thrombotic activities of PLY have been explored. Interestingly, these insights have coincided with the increasing recognition of the association of severe CAP, of which the pneumococcus remains the predominant bacterial pathogen, with the development of acute, often fatal, cardiovascular events [53].

Seemingly, the earliest study linking PLY to platelet activation was that described by Ohkuni et al. in 2011. These authors, in a study focused primarily on a comparison of the bioactivities of pore-forming toxins produced by Streptococcus suis, Streptococcus mitis and the pneumococcus, observed that all of these cytotoxins, at very high concentrations, promoted aggregation of human platelets present in platelet-rich plasma [54]. In the case of PLY, platelet aggregation was observed at remarkably high concentrations of the toxin [maximum aggregation of $60 \%$ at 30 micrograms $(\mu \mathrm{g}) / \mathrm{mL}$ PLY, in the setting of release of $20.5 \%$ platelet lactate dehydrogenase, a marker of PLY-mediated cytotoxicity] [54]. These authors did not, however, probe the mechanisms by which PLY induced platelet aggregation. 
More recently, Nel et al. reported that addition of recombinant PL, at much lower therapeutically-relevant concentrations of $10-80$ nanograms $(\mathrm{ng}) / \mathrm{mL}$, to platelet-rich plasma promoted dose-related aggregation of these cells in vitro [55]. Toxin-mediated platelet aggregation was dependent on sub-lytic pore formation, influx of extracellular $\mathrm{Ca}^{2+}$, and mobilisation of platelet $\alpha$-granules, resulting in upregulated expression of the adhesion molecule, P-selectin (CD62P), a potent mediator of homotypic aggregation of platelets [55]. These observations were subsequently confirmed independently [56]. The authors of this latter study, also using platelet-rich plasma, observed that PLY, albeit at the relatively high concentration of $0.8 \mu \mathrm{g} / \mathrm{mL}$, caused platelet aggregation, which was dependent on pore-forming activity, $\mathrm{Ca}^{2+}$ influx, and upregulation of expression of P-selectin [56].

PLY has also recently been reported in two different studies to induce heterotypic aggregation of neutrophils and platelets in vitro by mechanisms somewhat similar to those which promote homotypic aggregation of platelets. In the first of these, Zhang et al. reported that addition of recombinant PLY, at a concentration of $0.8 \mu \mathrm{g} / \mathrm{mL}$ to human whole blood, promoted the formation of neutrophil:platelet (NP) aggregates which was also dependent on pore-forming activity, $\mathrm{Ca}^{2+}$ influx, activation of myosin light chain kinase activity, $\alpha$-granule mobilisation and upregulated expression of P-selectin [57]. In the second study, Nel et al., using much lower concentrations of PLY (10-80 ng/mL), observed significant, dose-dependent formation of $\mathrm{N}: \mathrm{P}$ aggregates following addition of the toxin to mixed buffy layer cell suspensions prepared from human whole blood [58]. In addition to confirmeing the involvement of sub-lytic pore formation, $\mathrm{Ca}^{2+}$ influx and dependence on upregulated expression of P-selectin, these authors also documented the involvement of activation of protease-activated receptor 1 (PAR1) on platelets in sustaining the activation of these cells [58]. The putative proteases involved in activation of PAR1 appeared to be of neutrophilic origin [58].

The aforementioned findings are in keeping with two earlier studies which described P-selectin-mediated N:P aggregate formation following addition of the bacterial cholesterol-binding toxins, Streptococcus pyogenes-derived streptolysin O and Staphylococcus aureus-derived $\alpha$-haemolysin, to human whole blood in vitro $[59,60]$. The authors, who performed only limited mechanistic studies, linked these 
findings to the pathogenesis of vascular occlusions and tissue damage during infection with group A Streptococci [59] and to alveolar capillary destruction in haemorrhagic/necrotising pneumonia caused by methicillin-resistant $S$. aureus [60].The findings of these studies appear to support the contention that platelet homotypic and heterotypic aggregation is likely to be a common property of bacterial pore-forming toxins.

\section{Activation of the NLRP3 inflammasome as a potential mechanism of PLY- mediated platelet activation}

When fully assembled, the NLRP3 inflammasome plays a critical role in mediating the transition of the pro-inflammatory cytokines, interleukin-1 $\beta$ and IL-18, from a latent to a highly active state, a mechanism which is of particular importance in cells of the innate immune system, particularly neutrophils and monocytes/macrophages. Recently, the presence of all of the functional components of the NLRP3 inflammasome, as well as their corresponding RNA transcripts, has also been described in human platelets [61-63]. These components are the sensor protein NLRP3 (NOD-like receptor containing domain pyrin 3), the adaptor, ASC (apoptosisassociated speck-like protein containing a CARD domain), and the proteolytic subunit pro-caspase-1/caspase-1, as well as Bruton's tyrosine kinase, the latter having recently been reported to be a key additional component of the fully assembled NLRP3 inflammasome complex [64, 65]. Assembly and activation of the platelet NLRP3 inflammasome has been described following exposure of platelets to collagen or thrombin and is associated with intracellular co-localisation of NLRP3 and ASC and activation of caspase-1 [65]. The involvement of the activated NLRP3 inflammasome in collagen/thrombin-mediated activation of murine platelets is underscored by observations of attenuation of upregulated expression of P-selectin, platelet aggregation and in vitro thrombus formation in the presence of specific inhibitors of NLRP3 or caspase-1, as well as by selective ablation of NLRP3 [65].

Although the effects of PLY on activation of the NLRP3 inflammasome in human platelets have not, to our knowledge, been investigated, it is noteworthy that the toxin has been reported to activate the inflammasome in various types of cells of the innate immune system, including neutrophils [66] and dendritic cells [67]. In this 
context, it is now well recognised that efflux of $\mathrm{K}^{+}$is the "common trigger of NLRP3 inflammasome activation by bacterial toxins" [68], an activity of PLY which has been observed following treatment of neutrophils with the toxin in vitro [69] and which is a prerequisite for activation of the inflammasome in these cells.

Very recently, an alternative mechanism of PLY-mediated maturation of proIL-1 $\alpha$ and secretion of the active cytokine has been described in isolated murine peritoneal macrophages following ingestion of a PLY-expressing D39 strain of the pneumococcus, but not by a corresponding ply gene knockout strain of the pathogen [70]. This mechanism was dependent on internalisation of the pneumococcus by macrophages, influx of extracellular $\mathrm{Ca}^{2+}$ due to PLY-mediated formation of $\mathrm{Ca}^{2+}$ permeable membrane pores, and intracellular activation of the $\mathrm{Ca}^{2+}$-dependent cysteine proteinase, calpain, which, in turn, mediated cleavage of pro-IL-1 $\alpha$ to the active form of the cytokine [70]. Although the existence of this mechanism of conversion of pro-IL-1 $\beta$ to IL- $1 \alpha$ has not yet been described in human platelets, it is noteworthy that these cells, like macrophages, also possess calpain [71].

Although the aforementioned studies are consistent with the involvement of PLY, either directly or by implication, in platelet activation, it should be mentioned that one study failed to detect the involvement of PLY in activation of these cells. This study, which was primarily focused on the pro-adhesive interactions of the pneumococcus with TLR2, using aggregometry as a measure of platelet activation, reported, that a PLY-deficient strain of the pneumococcus was equally effective as its PLY-expressing counterparts in triggering platelet activation [40]. This finding may, however, be explained by the fact that PLY is only released extracellularly during the late stages of growth of the pneumococcus by autolysis, underscoring the importance of detection and measurement of toxin concentrations when investigating the effects of intact bacteria on eukaryotic cells, particularly in the context of negative findings. 


\section{Pneumococcus-derived hydrogen peroxide $\left(\mathrm{H}_{2} \mathrm{O}_{2}\right)$ as a potential mediator of platelet activation}

The pneumococcus is a prolific producer of $\mathrm{H}_{2} \mathrm{O}_{2}$ via activity of the enzyme pyruvate oxidase, achieving extracellular concentrations of this cell-permeant reactive oxygen species of up to $2 \mathrm{mM}$ during growth in bacteriological culture medium [72]. Although this seems potentially suicidal given that the pneumococcus does not produce catalase, this pathogen is seemingly well equipped with alternative anti-oxidant defences. These include the $\mathrm{H}_{2} \mathrm{O}_{2}$-scavenging activity of pneumococcal surface thioredoxin-fold lipoproteins [73], together with intracellular protection mediated via the activity of thiol peroxidase $\mathrm{D}$, thereby sustaining glycolysis, as well as capsule and nucleotide biosynthesis [74]. Pneumococcus-derived $\mathrm{H}_{2} \mathrm{O}_{2}$ functions not only as a mechanism of elimination of microbial competitors in the nasopharynx, but also as an effective virulence factor [75].

Although unexplored, $\mathrm{H}_{2} \mathrm{O}_{2}$ produced by platelet-adherent pneumococci has the potential to augment pathogen-mediated platelet activation. This contention is based on a series of earlier studies which reported that collagen-induced platelet activation, but not that activated by thrombin or ADP, was dependent on intracellular generation of $\mathrm{H}_{2} \mathrm{O}_{2}$ by these cells [76-78]. In addition, collagen-mediated platelet activation was potentiated by the addition of low concentrations $(\leq 5 \mu \mathrm{M})$ of reagent $\mathrm{H}_{2} \mathrm{O}_{2}$ [79]. These potentiating effects of $\mathrm{H}_{2} \mathrm{O}_{2}$, generated endogenously or added extracellularly, on platelet activation appear to be achieved via augmentation of the release of $\mathrm{Ca}^{2+}$ from intracellular storage vesicles, a key event in platelet activation $[80,81]$. The possible clinical significance of these findings is highlighted by the findings of a more recent study in which the time taken to achieve stable arterial occlusion following experimental photochemical injury of the carotid artery was found to be significantly shorter in 12- and 18-month-old mice when compared with 4month-old mice [82]. A similar increase in age-related susceptibility to venous thrombosis following ligation of the inferior vena cava was also observed [82]. The propensity of aged mice to develop these vascular abnormalities was associated with hyperactivity of platelets as a consequence of impaired intracellular anti-oxidant defences and increased production of $\mathrm{H}_{2} \mathrm{O}_{2}$. Restoration of platelet function was 
achieved by strategies which reinforced platelet anti-oxidant defence mechanisms [81].

Table 1: Mechanisms by which the pneumococcus promotes platelet aggregation and activation

\begin{tabular}{l} 
Mediator \\
\hline $\begin{array}{l}\text { Pneumococcal adhesin, } \\
\text { phosphorylcholine }\end{array}$ \\
Anti-pneumococcal lgG2 anti-capsular \\
antibodies and platelet factor 4
\end{tabular}

Complement activation by antipneumococcal antibodies of the $\lg \mathrm{G} 1$ and IgG2 subclasses

Pneumococcal adhesins, PavB and PspC

Pneumococcal cell wall component, lipoteichoic acid

Pneumococcal (phage-derived) adhesins, PblA and PblB

Pneumococcal pore-forming toxin, pneumolysin

Pneumococcus-derived hydrogen peroxide $\left(\mathrm{H}_{2} \mathrm{O}_{2}\right)$
May induce platelet aggregation via binding to the platelet-activating factor receptor

Pneumococci with surface-bound 27,28 platelet factor-4 and IgG antibodies bind to the platelet FcyRIIA which promotes activation of GPIIb/IIla and fibrinogen binding of platelets

Interaction of activated C1q, as well as $\mathrm{C} 3 \mathrm{a}$ and $\mathrm{C} 5 \mathrm{a}$ with their counterreceptors on platelets resulting in platelet activation

These bind to the GPIIb/IIla-fibrin32-35 thrombospondin-1 complex on the platelet surface to promote aggregation

Has been reported to promote platelet 16,40 aggregation and activation via interaction with platelet TLR2, but some uncertainty remains as to the existence of this mechanism

Attach to platelet membrane $45-50$ gangliosides promoting aggregation and activation of these cells

Promotes platelet aggregation and activation via pore formation-dependent influx of extracellular $\mathrm{Ca}^{2+}$ and possibly via activation of the NLRP3 inflammasome

$\mathrm{H}_{2} \mathrm{O}_{2}$ mediates platelet activation via release of $\mathrm{Ca}^{2+}$ from intracellular storage vesicles, but the existence of this mechanism is unproven in the context of pneumococcus-derived $\mathrm{H}_{2} \mathrm{O}_{2}$ 
These various mechanisms by which the pneumococcus promotes/may promote the aggregation and activation of human platelets by both receptordependent and -independent mechanisms are summarised in Table 1.

The following section of the review covers experimental animal studies, of which there are few, a larger number of clinical studies, mostly focused on all-cause CAP, which have implicated platelet activation measured by alterations in the numbers and/or activation status of these cells with outcome.

\section{Harmful consequences of platelet:pneumococcus interactions in vivo}

Platelets directly, as well as indirectly via their close contact with other cell types, particularly neutrophils and vascular endothelial cells, have been reported to participate in the early stages of host defence against infectious agents, including the pneumococcus [83]. Not only do platelets bring adherent bacteria into close proximity with neutrophils via formation of neutrophil:platelet heterotypic aggregates, but they also promote the formation of neutrophil extracellular traps (NETS) which immobilise and, in some cases kill, ensnared pathogens [reviewed in 84]. In this setting, platelet-driven NETosis appears to require both TLR4 signalling and the association of GPI $\beta$ with neutrophil $\beta 2$ integrins [84].

On the other hand, the interaction of bacterial pathogens with platelets is potentially harmful and may promote dissemination of pathogens as described for Streptococcus pyogenes in a murine model of experimental infection [85]. In addition, systemic hyperreactivity of platelets, leading to the formation of intravascular microthrombi and excessive, poorly controlled NETosis during severe bacterial infections, including Streptococcal infections, is well recognised, presenting the threat of widespread microvascular thrombosis and organ dysfunction [86-90].

\section{Experimental animal studies}

In the context of severe pneumococcal disease, intravascular activation of platelets has recently been demonstrated in a porcine model of experimental pneumococcal infection in which an invasive serotype 8 strain of the pathogen was used at low and 
high infective doses $\left(4.2 \times 10^{6}\right.$ vs $2.9 \times 10^{8}$ colony forming units $\left./ \mathrm{mL}\right)$ [91]. Infection by the intravenous route at the high, but not the low dose of the pneumococcus resulted in a transient decrease in the circulating platelet count at days 1-2 postinfection, which was associated with significant increases in platelet expression of Pselectin and fibrinogen binding both spontaneously and following activation of the cells with either adenosine-5'-diphosphate (ADP) or the pneumococcus in vitro [91].

In the case of PLY specifically, experimental animal studies (murine) targeting its involvement in acute lung and myocardial damage have largely focused on the direct injurious effects of the toxin on the pulmonary microvascular barrier [92, 93] and myocardium [94-97] respectively. Although these mechanisms are clearly of pathogenetic significance, the pro-thrombotic effects of the toxin, as well as the other aforementioned mechanisms of pneumococcus-mediated platelet activation, are also likely to contribute to organ damage and dysfunction.

\section{Clinical studies}

To our knowledge, the only study which has focused specifically on platelet activation and clinical outcome in pneumococcal as opposed to all-cause CAP is that mentioned above by Tunjungputri et al., who described the association of expression of the $p b / B$ gene by the pneumococcus with significantly increased platelet activation and 30-day mortality [50]. However, given that the pneumococcus is the most commonly encountered aetologic agent in CAP, an overview of platelet activation and its association with clinical indices of outcome in all-cause CAP appears warranted. The majority of studies of this type have focused on associations between alterations in the numbers of circulating platelets, mostly in relation to thrombocytopenia, measured on hospital/intensive care unit (ICU) admission, as an indicator of disseminated intravascular coagulation and microthrombosis, and associations thereof with clinical outcome.

In one of the earliest studies, Feldman et al. investigated clinical and laboratory determinants of outcome of patients $(n=73)$ with severe all-cause CAP admitted to an ICU [98]. These authors reported that $33 \%$ of patients $(n=24)$ presented with thrombocytopenia (platelet count $<140 \times 10^{9} / \mathrm{L}$ ), which was predictive of a poor prognosis $(P=0.02)$ [98]. The overall mortality rate was $53 \%(n=39)$ with 
$59 \%(n=23)$ of these succumbing to their infection within 5 days. Causative pathogens were isolated from either blood $(63 \%, n=46)$ or sputum $(15 \%, n=11)$ with the pneumococcus and Klebsiella pneumoniae accounting for $36 \%(n=26)$ and $31.5 \%(n=23)$ of these respectively. However, associations between type of pathogen and thrombocytopenia were not reported [98].

This issue was addressed in a subsequent, smaller ICU-based study by the same authors in which they investigated patients $(n=41)$ with bacteraemic CAP caused by either the pneumococcus $(n=21)$ or K. pneumoniae $(n=20)$ [99]. In this study, the authors reported that circulating platelet counts measured on presentation were significantly lower in patients with CAP caused by $K$. pneumoniae as opposed to disease caused by the pneumococcus ( $120 \pm 16 \times 10^{9} / \mathrm{L}$ vs. $254 \pm 30 \times 10^{9} / \mathrm{L}$ respectively, $P<0.005)$, which appeared to distinguish infection caused by the two different pathogens [99].

Following an interval of 16 years since the study reported by Feldman et al. in 1991 [99], the issue of the association of thrombocytopenia and outcome of patients admitted to ICU for severe CAP was re-visited in a multicentre observational study involving 822 patients undertaken by Brogly et al. [100]. The primary outcome measure was ICU mortality. Patients were stratified into three categories according to circulating platelet counts measured on admission to ICU, these being low ( $\leq 50 \mathrm{x}$ $\left.10^{9} / \mathrm{L}, \mathrm{n}=41\right)$, intermediate $\left(51-149 \times 10^{9} / \mathrm{L}, \mathrm{n}=161\right)$ and high $\left(\geq 150 \times 10^{9} / \mathrm{L}, \mathrm{n}=620\right)$. The total ICU mortality rate was $35.4 \%(n=291)$, while the differential mortality rates according to circulating platelet counts were $30.8 \%, 44.1 \%$ and $70.7 \%$ in the groups with high, intermediate and low platelet counts respectively $(P<0.0001)$, with thrombocytopenia of $\leq 50 \times 10^{9} / \mathrm{L}$ identified as an independent predictor of ICU mortality (AOR=4.386, $P=0.0014$ ) [100]. With respect to causative pathogens, these were identified in $60 \%(n=490)$ of patients with the pneumococcus being the most common aetiologic agent identified in $25 \%(n=205)$ of patients. Although the pneumococcus accounted for 59 (29\%) of the 202 patients in the combined low and intermediate platelet count groups, no significant associations were detected between any type of causative pathogen and thrombocytopenia [100]. 
In the context of associations of thrombocytopenia with ICU mortality, a later study by Claushuis et al. [101], although not focused primarily on CAP, is nevertheless noteworthy. In this study these authors, who investigated the prognostic potential of thrombocytopenia detected on admission of critically ill sepsis patients ( $n=929$ ) to ICU, reported similar findings to those described by Brogly et al. in the clinical setting of severe CAP [100, 101]. Claushuis et al. reported that patients with severe sepsis who had "very low" ( $\left.<50 \times 10^{9} / \mathrm{L}\right)$ or "intermediate-low" circulating platelet counts had significantly higher mortality rates \{hazard ratios (HRs) of 2.0[95\% Cl: $1.32-3.05]$ and 1.72 [95\%Cl: $1.22-2.44]$ respectively\} relative to those with "low" (100-149 x 10\% $/ \mathrm{L})$ or normal (150-399 x 10\% $/ \mathrm{L})$ platelet counts [101]. However, relationships between thrombocytopenia and type of causative pathogen were not interrogated in this study [101].

Continuing with CAP, Mirsaeidi et al. in 2010 reported the findings of a retrospective cohort study undertaken to investigate the association between platelet count measured on presentation and 30-day mortality in a cohort of patients $(n=500)$ hospitalised with CAP, which was diagnosed according to clinical, laboratory and radiological assessment, for whom no microbiological data was presented [102]. In this study, thrombocytopenia and thrombocytosis were based on circulating platelet counts of $<100 \times 10^{9} / \mathrm{L}$ and $>400 \times 10^{9} / \mathrm{L}$ respectively. A total of $54(10.8 \%)$ patients died within 30 days of hospital admission. Thrombocytosis and thrombocytopenia were detected in 65 (13\%) and 27 (5.4\%) patients respectively with 16 (25\%, $P<0.0001)$ and 5 (18\%, no $P$ value shown) deaths in each group. Multivariate analysis revealed a significant association of thrombocytosis with 30-day mortality (AOR $=3.268,95 \% \mathrm{Cl}: 1.578-6.770 ; P=0.001)$. Although the authors state that "likewise, low platelet counts were associated with an increased risk of mortality", levels of statistical significance were not shown [102].

In what appears to be the largest study of its kind to date, Prina et al. investigated the associations of thrombocytopenia and thrombocytosis with various indices of outcome in a prospective analysis of 2,423 consecutive, hospitalised patients with CAP [103]. Thrombocytopenia $(n=53,2 \%)$ and thrombocytosis $(n=204$, $8 \%$ ) detected on hospital admission were categorised as platelet counts of $<100 \mathrm{x}$ $10^{9} / \mathrm{L}$ and $\geq 4 \times 10^{9} / \mathrm{L}$ respectively. Patients with thrombocytopenia presented more 
frequently with severe sepsis $(P<0.001)$, septic shock $(P=0.009)$, need for invasive mechanical ventilation $(P<0.001)$ and need for ICU admission $(P=0.011)$, while those with thrombocytosis presented with a higher frequency of respiratory complications $(P<0.001)$ [103].

Patients with either thrombocytopenia or thrombocytosis were also found to have longer lengths of hospital stay $(P=0.004)$ and higher 30 -day mortality $(P=0.001)$ and readmission $(P=0.011)$ rates than patients with normal platelet counts [103], which in the case of thrombocytosis, but not thrombocytopenia, was confirmed by multivariate analysis ( $\mathrm{OR}=2.720 ; 95 \% \mathrm{Cl}: 1.589-4.657 ; P<0.001)$, possibly reflecting the smaller numbers in the thrombocytopenia group. With respect to aetiology, causative pathogens were isolated from 1060 (44\%) patients with the pneumococcus being the most commonly encountered $(n=530,22 \%)$. However, no significant associations were detected between the type of causative pathogen and platelet count. The authors concluded that "thrombocytosis has been proved to be a marker of poor outcome in CAP. Consequently it should be considered in the severity evaluation of patients with CAP and can help promptly identify patients at higher risk for respiratory complications" [103].

In a similar, but smaller prospective study to which 40 patients hospitalised for CAP were included, El Maraghy et al. investigated relationships between thrombocytopenia $\left(<150 \times 10^{9} / \mathrm{L}\right)$ and thrombocytosis $\left(>400 \times 10^{9} / \mathrm{L}\right)$ measured on hospital admission with 7 and 3 patients respectively falling into each category [104]. Despite the small numbers of patients, the authors reported that both thrombocytopenia and thrombocytosis were significantly associated with a higher occurrence of respiratory complications $(P=0.008)$, higher CURB65 scores $(P=0.002)$ and increased mortality $(P=0.05)$. Again, however, associations of either thromboytopenia or thrombocytosis with causative pathogens were not investigated.

A more recent study reported by Garin et al. [105] was based on a secondary analysis of an earlier multicentre randomised trial which evaluated the therapeutic efficacy of beta-lactam monotherapy versus beta-lactam/macrolide combination therapy in hospitalised patients $(n=580)$ with moderately severe CAP [106]. The secondary analysis was focused primarily on identifying predictors of early clinical 
stability (achieved within 72 hours) measured at hospital admission, including the circulating platelet count [105]. Of the total group, 293 patients achieved early clinical stability, while the remainder $(n=287)$ did not, the respective platelet counts (mean \pm $\mathrm{SD})$ for the two sub-groups being $221 \pm 91 \times 10^{9} / \mathrm{L}$ and $245 \pm 102 \times 10^{9} / \mathrm{L}(P=0.002)$. Even though these differences in platelet counts were small, albeit statistically significant, multivariate analysis using 2 different models with different predictor variables revealed that a lower platelet count was the only biological parameter independently associated with early clinical stability, which was evident in both models ( $P=0.001-P<0.001)$. In addition, analysis of distribution of platelet counts by deciles versus the proportion of patients who achieved early clinical stability, revealed a linear association $\left(R^{2}=0.73\right)[105]$.

The authors contend that their findings are consistent with an association between thrombocytosis and a poor clinical outcome possibly due to "more severe or prolonged lung inflammation". They also concede, however, that the exclusion of patients with severe pneumonia from their study, as well as the low frequency of patients with platelet counts of $<100 \times 10^{9} / \mathrm{L}$, may have resulted in failure to detect associations between thrombocytopenia and a worse outcome [105].

Causative pathogens were detected in $180(31 \%)$ patients with the pneumococcus being the most commonly encountered ( $n=88$ patients, $15.2 \%$ ); however, no associations were reported between type of pathogen and platelet count [105].

In another recent study, Gorelik et al. adopted a different approach to the aforementioned studies, all of which were based on a single circulating platelet count measured on hospital admission [107]. These authors investigated the predictive potential of thrombocytopenia and thrombocytosis measured on admission and discharge (minimum interval of 3 days) in relation to all-cause mortality recorded at 90 days, 3 years and at a medium of 4.5 years post-discharge (maximum follow-up interval of approximately 7 years) in adult patients ( $n=976$; mean age $64.6 \pm 21$ years) hospitalised for CAP [107]. On hospital admission/discharge, thrombocytopenia, normal platelet counts, and thrombocytosis were detected in $12.8 \%, 84.1 \%$ and $3.1 \%$ of patients respectively, with corresponding values on 
discharge of $6.4 \%, 84.4 \%$, and $9.2 \%$. Mortality rates did not differ significantly between patients with thrombocytopenia, normal platelet counts, or thrombocytosis measured on hospital admission ( $P=0.6$; overall in-hospital mortality of $6.3 \%)$. The overall 90-day, 3- and 4.5-year all-cause mortality rates were $11.2 \%, 27.6 \%$, and $29.2 \%$ respectively. With respect to categorisation according to platelet counts on admission/discharge, the all-cause mortality rates in patients with thrombocytopenia were $27.4 \%, 48.4 \%$ and $51.6 \%$, which were significantly higher $(P<0.001)$ than those of patients with normal platelet counts or thrombocytosis, the corresponding values for these categories being $10.2 \%, 26.9 \%$, and $35.4 \%$ and $8.9 \%, 17.8 \%$, and $24.4 \%$ respectively [107].

In addition, Gorelik et al. also investigated the potential of the difference in platelet count $(\triangle \mathrm{PC})$ measured on admission and discharge to predict all-cause mortality [107]. Patients were categorised in three groups, A ( $n=77), B(n-454)$, and $C(n=445)$ with decreasing, stable and increasing $\triangle P C$ values respectively. The $90-$ day, 3- and 4.5-year all-cause mortality rates were significantly higher $(P<0.001)$ in group A patients $(40.3 \%, 63.6 \%$, and $72.7 \%)$ than those in groups B $(12.3 \%, 31.5 \%$, and $39 \%)$ and $C(4.9 \%, 17.3 \%$, and $25.4 \%)$ [107]. With respect to the entire cohort of patients, the authors also observed that each $100 \times 10^{9}$ increment in $\triangle \mathrm{PC}$ strongly predicted lower mortality $(R=0.73 ; 95 \% \mathrm{Cl}: 0.64-0.83, P<0.001)$. Seemingly in contrast to the report by Garin et al. [105], Gorelik et al. concluded that a "rising PC throughout hospitalization is a powerful predictor of better survival, while a declining PC predicts poor outcome" [107].

The types of causative pathogen were not mentioned in this study [107].

A probable consensus interpretation of the aforementioned clinical studies, which are summarised in Table 2, is that severe neutropenia ( $\left.\leq 50 \times 10^{9} / \mathrm{L}\right)$ measured on hospital/ICU admission results from pathogen-mediated systemic activation of platelets, and as such is predictive of disease severity and a poor outcome. Likewise, infection-related thrombocytosis may underpin the association between elevated platelet counts and a poor outcome as reported in several studies. However, interpretation in this setting may be complicated by a high pre-existing platelet count in patients with comorbidities such as diabetes mellitus [108]. 
Table 2: Summary of studies which have evaluated relationships between circulating platelet counts and clinical outcome in hospitalised patients with all-cause CAP

\begin{tabular}{|c|c|c|}
\hline Authors & Patients (n) & Findings \\
\hline Feldman et al., 1989 [98] & $\begin{array}{c}\mathrm{n}=73 \\
\text { admitted to ICU }\end{array}$ & $\begin{array}{l}\text { Platelet counts of }<140 \times 10^{9} / \mathrm{L} \text { measured on } \\
\text { admission predictive of a poor prognosis }\end{array}$ \\
\hline Feldman et al., 1991 [99] & $\begin{array}{c}\mathrm{n}=41 \\
\text { admitted to ICU }\end{array}$ & $\begin{array}{l}\text { Lowest platelet counts detected in patients infected } \\
\text { with } K . \text { pneumoniae }\left(120 \pm 16 \times 10^{9} / \mathrm{L}\right) \text { in } \\
\text { comparison to those infected with the } \\
\text { pneumococcus }\left(254 \pm 30 \times 10^{9} / \mathrm{L}\right)\end{array}$ \\
\hline Brogly et al., 2007 [100] & $\begin{array}{l}\mathrm{n}=822 \\
\text { admitted to ICU }\end{array}$ & $\begin{array}{l}\text { Highest mortality observed in those with platelet } \\
\text { counts of } \leq 50 \times 10^{9} / \mathrm{L} \text { which was also an } \\
\text { independent predictor of ICU mortality }\end{array}$ \\
\hline Mirsaeidi et al., 2010 [102] & $\begin{array}{l}\mathrm{n}=500 \\
\text { hospitalised }\end{array}$ & $\begin{array}{l}\left.\text { Thrombocytosis ( }>400 \times 10^{y} / \mathrm{L}\right) \text {, a significant } \\
\text { predictor of mortality; "low platelet counts also } \\
\text { associated with an increased risk of mortality" }\end{array}$ \\
\hline Prina et al., 2013 [103] & $\begin{array}{c}\mathrm{n}=2423 \\
\text { hospitalised }\end{array}$ & $\begin{array}{l}\text { Significantly higher 30-day mortality rates recorded } \\
\text { in patients with either thrombocytopenia or } \\
\text { thrombocytosis, confirmed by multivariate analysis } \\
\text { only in the latter group, possibly due to lower } \\
\text { numbers in the former }\end{array}$ \\
\hline El Maraghy et al., 2015 [104] & $\begin{array}{l}\mathrm{n}=40 \\
\text { hospitalised }\end{array}$ & $\begin{array}{l}\text { Significantly increased mortality observed in } \\
\text { patients with either thrombocytopenia or } \\
\text { thrombocytosis }\end{array}$ \\
\hline Garin et al., 2016 [105] & $\begin{array}{c}\mathrm{n}=500 \\
\text { hospitalised for } \\
\text { "moderately severe } \\
\text { CAP" }\end{array}$ & $\begin{array}{l}\text { Thrombocytosis associated with a poor clinical } \\
\text { outcome (fewer patients achieving early clinical } \\
\text { stability); the possible influence of } \\
\text { thrombocytopenia was difficult to evaluate due to } \\
\text { the low number of patients with platelet counts } \\
\text { of }<100 \times 10^{9} / \mathrm{L}\end{array}$ \\
\hline Gorelik et al., 2017 [107] & $\mathrm{n}=976$ & $\begin{array}{l}\text { Demonstrated relationships between circulating } \\
\text { platelet counts and all-cause mortality at } 90 \text { days, } 3 \\
\text { years and a median of } 4.5 \text { years post-discharge. } \\
\text { They observed that thrombocytopenia detected } \\
\text { during hospitalisation was a significant predictor of } \\
\text { all-cause mortality at all } 3 \text { time intervals }\end{array}$ \\
\hline
\end{tabular}

Although causative pathogens were identified in 5 of the abovementioned studies, only 3 of these attempted, albeit unsuccessfully, to identify possible associations between type of pathogen and circulating platelet count measured on hospital/ICU admission. This may reflect low-level pathogen identification in several of these studies in the setting of low numbers of patients presenting with either thrombocytopenia or thrombocytosis. 


\section{Systemic biomarkers of platelet activation in CAP}

Although clinical studies in CAP are few, the inclusion of measurement of systemic biomarkers of platelet activation on hospital/ICU admission is likely to strengthen studies which are focused on linking alterations in circulating platelet counts to clinical indices of disease outcome and mortality. Inclusion of measurement of biomarkers of platelet activation with predictive potential is of particular importance given that about one third of patients hospitalised for CAP experience intra-hospital cardiovascular events, including heart failure, atrial fibrillation, myocardial infarction, ischaemic stroke and deep venous thrombosis [53]. In what appear to be the only two such studies undertaken to date in CAP, Cangemi et al. have reported that elevated plasma concentrations of soluble CD40 ligand and soluble P-selectin (CD62P), as well as serum levels of thromboxane $B_{2}$ and NOX2-dipeptide measured on hospital admission in patients with CAP $(n=278)$ were associated with early development of myocardial infarction [11, 109]. A noteworthy caveat, however, is that none of these biomarkers is platelet-specific. In this context, combined measurement of the platelet $\alpha$-granule CXC chemokines, platelet factor- 4 and betathromboglobulin seemingly offers a more selective approach [110,111]. Additional recently reported systemic biomarkers of platelet activation, albeit untested in CAP and possibly lacking selectivity, include histone $\mathrm{H} 3$ [112] and possibly histone $\mathrm{H} 4$ [113], as well as microRNAs, specifically miR-126, which has a strong association with platelet activation and risk of myocardial infarction [114-116]. Given the range of potential platelet-derived biomarkers [31], it is possible that others may be found which have comparable or even superior predictive potential to those described above.

More direct approaches to detect systemic activation of platelets in patients with CAP include flow cytometric detection of spontaneous neutrophi/platelet and monocyte/platelet aggregation in whole blood $[111,117,118]$.

The various systemic biomarkers of platelet activation are summarised in Table 3. 
Table 3: Circulating biomarkers of platelet activation

\begin{tabular}{lcc}
\multicolumn{1}{c}{ Biomarker } & Selectivity* & Ref \\
\hline Soluble CD40 ligand & $N$ & 11,109 \\
Soluble P-selectin (CD62P) & $N$ & 11,109 \\
Thromboxane B & N & 11,109 \\
NOX-2 dipeptide & N & 11,109 \\
Platelet factor 4 & Y & 110,111 \\
Beta-thromboglobulin & $\mathrm{Y}$ & 110,111 \\
Histone H3 & $\mathrm{N}$ & 112 \\
Histone H4 & $\mathrm{N}$ & 113 \\
MicroRNA, mcR-126 & $?$ & $114-116$ \\
Flow cytometric detection of spontaneous \\
neutrophil/platelet aggregates in whole blood
\end{tabular}

*Selectivity as a biomarker of platelet activation; $\mathrm{N}=\mathrm{No} ; \mathrm{Y}=\mathrm{Yes}$; ? = Uncertain

\section{Conclusion}

The contention that direct activation of platelets by the pneumococcus in particular, as well as by other types of CAP pathogen, may be involved in the pathogenesis of acute myocardial injury and the associated high prevalence of acute cardiovascular events in patients with severe CAP must be tempered by an awareness of alternative mechanisms of pathogenesis. This is particularly so in the case of the pneumococcus for which direct myocardial invasion and PLY-mediated cardiotoxicity have been described in murine and non-human primate models of experimental pneumococcal infection [94-97,119], as well as in limited human studies [94]. It does seem likely, however, that pneumococcus-mediated platelet activation may act in concert with myocardial invasion and the cardiotoxicity of PLY exacerbate the threat of myocardial injury. Nonetheless, more compelling evidence is necessary to strengthen the involvement of pneumococcus-mediated platelet activation not only in 
myocardial injury, but also acute lung injury and other types of organ damage. This may emerge from future clinical studies which combine measurements of alterations in the numbers of circulating platelets with that of selective, systemic biomarkers of platelet activation and cardiac injury. This, in turn, may guide a more discerning clinical application of adjuvant anti-platelet therapies in pneumococcal, as well as allcause CAP.

\section{References}

1. World Health Organization (WHO). The top 10 causes of death. Updated January 2017. Available from: http://www.who.int/mediacentre/factsheets/fs310/en/.

2. Waterer G. Respiratory infections in the Asia-Pacific region. Respirology 2017; 22(6): 1061.

3. Statistics South Africa. Mortality and causes of death in South Africa, 2011: Findings from death notification. Statistical Release p0309.3. Available from: www.statssa.gov.za/publications/P03093/P030932011.pdf

4. Office for National Statistics. Mortality statistics: deaths registered in England and Wales (Series DR); 2012. Available from:

https://data.gov.uk/dataset/mortality statisticsdeaths registered in england and wales series $\mathrm{dr}$

5. Rae N, Finch S, Chalmers JD. Cardiovascular disease as a complication of community-acquired pneumonia. Curr Opin Pulm Med 2016; 22(3): 212-218.

6. Waterer GW. Community-acquired pneumonia: A global perspective. Semin Respir Crit Care Med 2016; 37(6): 799-805.

7. Sanz Herrero F, Blanguer Olivas J. Microbiology and risk factors for communityacquired pneumonia. Semin Respir Crit Care Med 2012; 33(3): 220-231.

8. Feldman C, Anderson R. The role of Streptococcus pneumoniae in communityacquired pneumonia. Semin Respir Crit Care Med 2016; 37(6): 806-818.

9. Stupka JE, Mortensen EM, Anzueto A, Restrepo MI. Community-acquired pneumonia in elderly patients. Aging Health 2009; 5(6): 763-774.

10. United Nations, Department of Economic and Social Affairs, Population Division. World Population Ageing 2015 (ST/ESA/SER.A/390). Available from: 
www.un.org/en/development/desa/population/publications/pdf/ageing/WPA2015

\section{Report.pdf}

11. Cangemi R, Casciaro M, Rossi E, Calvieri C, Bucci T, Calabrese CM, et al; SIXTUS Study Group. Platelet activation is associated with myocardial infarction in patients with pneumonia. J Am Coll Cardiol 2014; 64(18): 1917-1925.

12. Guckian JC. Effect of pneumococci on blood clotting, platelets, and polymorphonuclear leukocytes. Infect Immun1975; 12(4): 910-918.

13. Ohman KP, Yun JC Keiser HR. Interaction of prostaglandins with adenosine diphosphate induced increase in cytosolic free calcium in human platelets. Scand J Clin Lab Invest 1992; 52(6): 483-490.

14. Totani L, Piccoli A, Dell'Elba G, Concetta A, Di Santo A, Martelli N, et al. Phosphodiesterase type 4 blockade prevents platelet-mediated neutrophil recruitment at the site of vascular injury. Arterioscler Thromb Vasc Biol 2014; 34(8): 1689-1696.

15. Cabellos C, Maclntyre DE, Forrest M, Burroughs M, Prasad S, Tuomanen E. Differing roles for platelet-activating factor during inflammation of the lung and subarachnoid space. The special case of Streptococcus pneumoniae. J Clin Invest 1992; 90(2): 612-618.

16. de Stoppelaar SF, Claushuis TA, Schaap MC, Hou B, van der Poll T, Nieuwland $\mathrm{R}$, et al. Toll-like receptor signalling is not involved in platelet response to Streptococcus pneumoniae in vitro or in vivo. PLoS One 2016; 11(6): e0156977.

17. Hamzeh-Cognasse H, Damien P, Chabert A, Pozzetto B, Cognasse F, Garraud O. Platelets and infections - complex interactions with bacteria. Front Immunol 2015; 6: 82.

18. van der Sluijs KF, van Elden LJ, Nijhuis M, Schuurman R, Florquin S, Shimizu T, et al. Involvement of the platelet-activating factor receptor in host defense against Streptococcus pneumoniae during postinfluenza pneumonia. Am J Physiol Lung Cell Mol Physiol 2006; 290(1): L194-L199.

19. Sørensen UB, Agger R, Bennedsen J, Henrichsen J. Phosphorylcholine determinants in six pneumococcal capsular polysaccharides detected by monoclonal antibody. Infect Immun 1984; 43(3): 876-878.

20. Kuckleburg CJ, Elswaifi SF, Inzana TJ, Czuprynski CJ. Expression of phosphorylcholine by Histophilus somni induces bovine platelet aggregation. Infect Immun 2007; 75(2): 1045-1049. 
21. Riaz AH, Tasma BE, Woodman ME, Wooten RM, Worth RG. Human platelets efficiently kill IgG-opsonized E. coli. FEMS Immunol Med Microbiol 2012; 65(1): 78-83.

22. Stocker TJ, Ishikawa-Ankerhold H, Massberg S, Schulz C. Small but mighty: Platelets as central effectors of host defense. Thromb Haemost 2017; 117(4): 651-661.

23. Moens L, Van Hoeyveld E, Verhaegen J, De Boeck K, Peetermans WE, Bossuyt X. Fcy-receptor IIA genotype and invasive pneumococcal infection. Clin Immunol 2006; 118(1): 20-23.

24. Bruhns $P$, lannascoli $B$, England $P$, Mancardi DA, Fernandez N, Jorieux $S$, et al. Specificity and affinity of human $\mathrm{Fcy}$ receptors and their polymorphic variants for human IgG subclasses. Blood 2009; 113(16): 3716-3725.

25. Moriarty RD, Cox A, McCall M, Smith SG, Cox D. Escherichia coli induces platelet aggregation in an FcyRlla-dependent manner. J Thromb Haemost 2016; 14(4): 797-806.

26. Michaelsen TE, Garred P, Aase A. Human IgG subclass pattern of inducing complement-mediated cytolysis depends on antigen concentration and to a lesser extent on epitope patchiness, antibody affinity and complement concentration. Eur J Immunol 1991; 21(1): 11-16.

27. Arman M, Krauel K, Tilley DO, Weber C, Cox D, Greinacher A, et al. Amplification of bacteria-induced platelet activation is triggered by FcyRIIA, integrin allb $\beta 3$, and platelet factor 4. Blood 2014; 123(20): 3166-3174.

28. Naik UP. Bacteria exploit platelets. Blood 2014; 123(20): 3067-3068.

29. Saeland E, Vidarsson G, Leusen JH, van Garderen E, Nahm MH, Vile-Weekhout $\mathrm{H}$, et al. Central role of complement in passive protection by human IgG1 and IgG2 anti-pneumococcal antibodies in mice. J Immunol 2003; 170(12): 61586164.

30. Patzelt J, Verschoor A, Langer HF. Platelets and the complement cascade in atherosclerosis. Front Physiol 2015; 6: 49

31. Mancuso ME, Santagostino E. Platelets: much more than bricks in a breached wall. Br J Haematol 2017; 178(2): 209-219. doi: 10.1111/bjh. 14653.

32. Niemann S, Kehrel BE, Heilmann C, Rennemeier C, Peters G, Hammerschmidt S. Pneumococcal association to platelets is mediated by soluble fibrin and supported by thrombospondin-1. Thromb Haemost 2009; 102(4): 735-742. 
33. Thorsen LI, Brosstad F, Gogstad G, Sletten K, Solum NO. Binding of ${ }^{125}$-labelled fibrin(ogen) fragments to platelets and to immunoprecipitated glycoprotein Ilb-IIla complex. Thromb Res 1986; 42(5): 645-659.

34. Binsker U, Kohler TP, Krauel K, Kohler S, Schwertz H, Hammerschmidt S. Pneumococcal adhesins PavB and PspC are important for the interplay with human thrombospondin-1. J Biol Chem 2015; 290(23): 14542-14555.

35. Binsker U, Kohler TP, Krauel K, Kohler S, Habermeyer J, Schwertz H, et al. Serotype 3 pneumococci sequester platelet-derived human thrombospondin-1 via the adhesion and immune evasion protein Hic. J Biol Chem 2017; 292(14): 57705783.

36. Niemann S, Spehr N, Van Aken H, Morgenstern E, Peters G, Herrmann M, et al. Soluble fibrin is the main mediator of Staphylococcus aureus adhesion to platelets. Circulation 2004; 110(2): 193-200.

37. Zhang G, Han J, Welch EJ, Ye RD, Voyno-Yasenetskaya TA, Malik AB, et al. Lipopolysaccharide stimulates platelet secretion and potentiates platelet aggregation via TLR4/MyD88 and the cGMP-dependent protein kinase pathway. $J$ Immunol 2009; 182(12): 7997-8004.

38. Kälvegren H, Skoglund C, Helldahl C, Lerm M, Grenegård M, Bengtsson T. Tolllike receptor 2 stimulation of platelets is mediated by purinergic P2X1-dependent $\mathrm{Ca}^{2+}$ mobilisation, cyclooxygenase and purinergic $\mathrm{P} 2 \mathrm{Y} 1$ and $\mathrm{P} 2 \mathrm{Y} 12$ receptor activation. Thromb Haemost 2010; 103(2): 398-407.

39. Rivadeneyra L, Carestia A, Etulain J, Pozner RG, Fondevila C, Negrotto S, et al. Regulation of platelet responses triggered by Toll-like receptor 2 and 4 ligands is another non-genomic role of nuclear factor-kappaB. Thromb Res 2014; 133(2): 235-243.

40. Keane C, Tilley D, Cunningham A, Smolenski A, Kadioglu A, Cox D, et al. Invasive Streptococcus pneumoniae trigger platelet activation via Toll-like receptor 2. J Thromb Haemost 2010; 8(12): 2757-2765.

41. Cognasse F, Hamzeh H, Chavarin P, Acquart S, Genin C, Garraud O. Evidence of Toll-like receptor molecules on human platelets. Immunol Cell Biol 2005; 83(2): 196-198.

42. Berthet J, Damien P, Hamzeh-Cognasse H, Pozzetto B, Garraud O, Cognasse F. Toll-like receptor 4 signal transduction in platelets: novel pathways. $\mathrm{Br} \mathrm{J}$ Haematol 2010; 151(1): 89-92. 
43. Damien P, Cognasse F, Payrastre B, Spinelli SL, Blumberg N, Arthaud CA, et al. NF-KB links TLR2 and PAR1 to soluble immunomodulatory factor secretion in human platelets. Front Immunol 2017; 8: 85.

44. Bensing BA, Siboo IR, Sullam PM. Proteins PbIA and PbIB of Streptococcus mitis, which promote binding to human platelets, are encoded within a lysogenic bacteriophage. Infect Immun 2001; 69(10): 6186-6192.

45. Mitchell J, Siboo IR, Takamatsu D, Chambers HF, Sullam PM. Mechanism of cell surface expression of the Streptococcus mitis platelet binding proteins PbIA and PblB. Mol Microbiol 2007; 64(3): 844-857.

46. Siboo IR, Bensing BA, Sullam PM. Genomic organization and molecular characterization of SM1, a temperate bacteriophage of Streptococcus mitis. $J$ Bacteriol 2003; 185(23): 6968-6975.

47. Stanley E, Fitzgerald GF, Le Marrec C, Fayard B, van Sinderen D. Sequence analysis and characterization of phi O1205, a temperate bacteriophage infecting Streptococcus thermophiles CNRZ12205. Microbiology 1997; 143(Pt 11): 34173429.

48. Mitchell J, Sullam PM. Streptococcus mitis phage-encoded adhesins mediate attachment to a2-8-linked sialic acid residues on platelet membrane gangliosides. Infect Immun 2009; 77(8): 3485-3490.

49. Hsieh YC, Lin TL, Lin CM, Wang JT. Identification of PblB mediating galactosespecific adhesion in a successful Streptococcus pneumoniae clone. Sci Rep 2015; 5: 12265.

50. Tunjungputri RN, Mobegi FM, Cremers AJ, van der Gaast-de Jongh CE, Ferwerda G, Meis JF, et al. Phage-derived protein induces increased platelet activation and is associated with mortality in patients with invasive pneumococcal disease. MBio 2017; 8(1): e01984-16.

51. Mitchell TJ, Dalziel CE. The biology of pneumolysin (Chapter 8). In: MAPCF/CDC Proteins - Agents of Defence, Attack and Invasion. Eds. G. Anderluh and R. Gilbert. Published by Springer Science+Business Media, Dordrecht. ISBN 97894-017-8880-9. Subcellular Biochemistry 2014; 80: 145-160. Doi: 10.1007/97894-017-8881-6_8.

52. Anderson R, Feldman C. Pneumolysin as a potential therapeutic target in severe pneumococcal disease. J Infect 2017; 74(6): 527-544. 
53. Violi F, Cangemi R, Falcone M, Taliani G, Pieralli F, Vannucchi V, et al. Cardiovascular complications and short-term mortality risk in community-acquired pneumonia. Clin Infect Dis 2017; 64(11): 1486-1493.

54. Ohkuni H, Nagamune H, Ozaki N, Tabata A, Todome $\mathrm{Y}$, Watanabe $\mathrm{Y}$, et al. Characterization of recombinant Streptococcus mitis-derived human platelet aggregation factor. APMIS 2012; 120(1): 56-71.

55. Nel JG, Durandt C, Mitchell TJ, Feldman C, Anderson R, Tintinger GR. Pneumolysin mediates platelet activation in vitro. Lung 2016; 194(4): 589-593.

56. Zhang S, Wang J, Chen S, Yin J, Pan Z, Liu K, et al. Effects of suilysin on Streptococcus suis-induced platelet aggregation. Front Cell Infect Microbiol 2016; 6: 128.

57. Zhang S, Zheng Y, Chen S, Huang S, Liu K, Lv Q, et al. Suilysin-induced plateletneutrophil complexes formation is triggered by pore formation-dependent calcium influx. Sci Rep 2016; 6: 36787.

58. Nel JG, Durandt C, Theron AJ, Tintinger GR, Pool R, Richards GA, et al. Pneumolysin mediates heterotypic aggregation of neutrophils and platelets in vitro. J Infect 2017; 74(6): 599-608.

59. Bryant AE, Bayer CR, Chen RY, Guth PH, Wallace RJ, Stevens DL. Vascular dysfunction and ischemic destruction of tissue in Streptococcus pyogenes infection: the role of streptolysin O-induced platelet/neutrophil complexes. J Infect Dis 2005; 192(6): 1014-1022.

60. Parimon T, Li Z, Bolz DD, McIndoo ER, Bayer CR, Stevens DL, et al. Staphylococcus aureus $\alpha$-hemolysin promotes platelet-neutrophil aggregate formation. J Infect Dis 2013; 208(5): 761-770.

61. Hottz ED, Lopes JF, Freitas C, Valls-de-Souza R, Oliveira MF, Bozza MT, et al. Platelets mediate increased endothelium permeability in dengue through NLRP3inflammasome activation. Blood 2013; 122(20): 3405-3414.

62. Rowley JW, Oler AJ, Tolley ND, Hunter BN, Low EN, Nix DA, et al. Genome-wide RNA-seq analysis of human and mouse platelet transcriptomes. Blood 2011; 118(14): e101-e111.

63. Hottz ED, Monteiro AP, Bozza FA, Bozza PT. Inflammasome in platelets: allying coagulation and inflammation in infectious and sterile diseases? Mediators Inflamm 2015; 2015: 435783. 
64. Ito M, Shichita T, Okada M, Komine R, Noguchi Y, Yoshimura A, et al. Bruton's tyrosine kinase is essential for NLRP3 inflammasome activation and contributes to ischaemic brain injury. Nat Commun 2015; 6: 7360.

65. Murthy P, Durco F, Miller-Ocuin JL, Takedai T, Shankar S, Liang X, et al. The NLRP3 inflammasome and Bruton's tyrosine kinase in platelets co-regulate platelet activation, aggregation, and in vitro thrombus formation. Biochem Biophys Res Commun 2017; 483(1): 230-236.

66. Karmakar M, Katsnelson M, Malak HA, Greene NG, Howell SJ, Hise AG, et al. Neutrophil IL-1 $\beta$ processing induced by pneumolysin is mediated by the NLRP3/ASC inflammasome and caspase- 1 activation and is dependent on $\mathrm{K}^{+}$ efflux. J Immunol 2015; 194(4): 1763-1775.

67. McNeela EA, Burke A, Neill DR, Baxter C, Fernandes VE, Ferreira D, et al. Pneumolysin activates the NLRP3 inflammasome and promotes proinflammatory cytokines independently of TLR4. PLoS Pathog 2010; 6(11): e1001191.

68. Cockeran R, Theron AJ, Steel HC, Matlola NM, Mitchell TJ, Feldman C, et al. Proinflammatory interactions of pneumolysin with human neutrophils. J Infect Dis 2001; 183(4): 604-611.

69. Muñoz-Planillo R, Kuffa P, Martinez-Colón G, Smith BL, Rajendiran TM, Núñez G. $\mathrm{K}^{+}$efflux is the common trigger of NLRP3 inflammasome activation by bacterial toxins and particulate matter. Immunity 2013; 38(6): 1142-1153.

70. Fang R, Wu R, Du H, Jin M, Liu Y, Lei G, et al. Pneumolysin-dependent calpain activation and IL-1 $\alpha$ secretion in macrophages infected with Streptococcus pneumoniae. Infect Immun 2017; doi: 10.1128/IAI.00201-17 [Epub ahead of print].

71. Kraemer BF, Weyrich AS, Lindemann S. Protein degradation systems in platelets. Thromb Haemost 2013; 110(5): 920-924.

72. Pericone CD, Park S, Imlay JA, Weiser JN. Factors contributing to hydrogen peroxide resistance in Streptococcus pneumoniae include pyruvate oxidase $(\mathrm{SpxB})$ and avoidance of the toxic effects of the Fenton reaction. J Bacteriol 2003; 185(23): 6815-6825.

73. Saleh M, Bartual SG, Abdullah MR, Jensch I, Asmat TM, Petruschka L, et al. Molecular architecture of Streptococcus pneumoniae surface thioredoxin-fold lipoproteins crucial for extracellular oxidative stress resistance and maintenance of virulence. EMBO Mol Med 2013; 5(12): 1852-1870. 
74. Lisher JP, Tsui HC, Ramos-Montañez S, Hentchel KL, Martin JE, Trinidad JC, et al. Biological and chemical adaptation to endogenous hydrogen peroxide production in Streptococcus pneumoniae D39. mSphere 2017; 2(1): e00291-16.

75. Feldman C, Anderson R, Cockeran R, Mitchell T, Cole P, Wilson R. The effects of pneumolysin and hydrogen peroxide, alone and in combination, on human ciliated epithelium in vitro. Respir Med 2002; 96(8): 580-585.

76. Del Principe D, Menichelli A, De Matteis W, Di Giulio S, Giordani M, Savini I, et al. Hydrogen peroxide is an intermediate in the platelet activation cascade triggered by collagen, but not by thrombin. Thromb Res 1991; 62(5): 365-375.

77. Pignatelli P, Pulcinelli FM, Lenti L, Gazzaniga PP, Violi F. Hydrogen peroxide is involved in collagen-induced platelet activation. Blood 1998; 91(2): 484-490.

78. Pignatelli P, Pulcinelli FM, Lenti L, Gazzaniga PP, Violi F. Vitamin E inhibits collagen-induced platelet activation by blunting hydrogen peroxide. Arterioscler Thromb Vasc Biol 1999; 19(10): 2542-2547.

79. Pratico D, Iuliano L, Pulcinelli FM, Bonavita MS, Gazzaniga PP, Violi F. Hydrogen peroxide triggers activation of human platelets selectively exposed to nonaggregating concentrations of arachidonic acid and collagen. $J$ Lab Clin Med 1992; 119(4): 364-370.

80. Loiko EN, Samal AB, Shulyakovskaya SM. $\mathrm{H}_{2} \mathrm{O}_{2}$-induced platelet aggregation and increase in intracellular $\mathrm{Ca}^{2+}$ concentration are blocked by inhibitors of intracellular signaling. Biochemistry 2003; 668(11): 1210-1216.

81. Redondo PC, Salido GM, Pariente JA, Rosado JA. Dual effect of hydrogen peroxide on store-mediated calcium entry in human platelets. Biochem Pharmacol 2004; 67(6): 1065-1076.

82. Dayal S, Wilson KM, Motto DG, Miller FJ Jr, Chauhan AK, Lentz SR. Hydrogen peroxide promotes aging-related platelet hyperactivation and thrombosis. Circulation 2013; 127(12): 1308-1316.

83. van den Boogaard FE, Schouten M, de Stoppelaar SF, Roelofs JJ, Brands X, Schultz MJ, et al. Thrombocytopenia impairs host defense during murine Streptococcus pneumoniae pneumonia. Crit Care Med 2015; 43(3): e75-e83.

84. Carestia A, Kaufman T, Schattner M. Platelets: new bricks in the building of neutrophil extracellular traps. Front Immunol 2016; 7: 271.

85. Kahn F, Hurley S, Shannon O. Platelets promote bacterial dissemination in a mouse model of streptococcal sepsis. Microbes Infect 2013; 15(10-11): 669-676. 
86. Fitzgerald JR, Foster TJ, Cox D. The interaction of bacterial pathogens with platelets. Nat Rev Microbiol 2006; 4; 445-457.

87. Jia M, Xiong Y, Lu H, Li R, Wang T, Ye Y, et al. Platelet activation is a key event in the pathogenesis of streptococcal infections. Front Biosci 2015; 20: 910-918.

88. Davis RP, Miller-Dorey S, Jenne CN. Platelets and coagulation in infection. Clin Transl Immunology 2016; 5(7): e89.

89. Deppermann C, Kubes P. Platelets and infection. Semin Immunol 2016; 28(6): 536-545.

90. McDonald B, Davis RP, Kim SJ, Tse M, Esmon CT, Kolaczkowska E, et al. Platelets and neutrophil extracellular traps collaborate to promote intravascular coagulation during sepsis in mice. Blood 2017; 129(10): 1357-1367.

91. Tunjungputri RN, de Jonge MI, de Greeff A, van Selm S, Buys H, HardersWesterveen JF, et al. Invasive pneumococcal disease leads to activation and hyperreactivity of platelets. Thromb Res 2016; 144: 123-126.

92. Witzenrath M, Gutbier B, Hocke AC, Schmeck B, Hippenstiel S, Berger K, et al. Role of pneumolysin for the development of acute lung injury in pneumococcal pneumonia. Crit Care Med 2006; 34(7): 1947-1954.

93. Witzenrath M, Gutbier B, Owen JS, Schmeck B, Mitchell TJ, Mayer K, et al. Role of platelet-activating factor in pneumolysin-induced acute lung injury. Crit Care Med 2007; 35(7): 1756-1762.

94. Brown AO, Mann B, Gao G, Hankins JS, Humann J, Giardina J, et al. Streptococcus pneumoniae translocates into the myocardium and forms unique microlesions that disrupt cardiac function. PLoS Pathog 2014; 10(9): e1004383.

95. Alhamdi Y, Neill DR, Abrams ST, Malak HA, Yahya R, Barrett-Jolley R, et al. Circulating pneumolysin is a potent inducer of cardiac injury during pneumococcal infection. PLoS Pathog 2015; 11(5): e1004836.

96. Gilley RP, González-Juarbe N, Shenoy AT, Reyes LF, Dube PH, Restrepo MI, et al. Infiltrated macrophages die of pneumolysin-mediated necroptosis following pneumococcal myocardial invasion. Infect Immun 2016; 84(5): 1457-1469.

97. Shenoy AT, Brissac T, Gilley RP, Kumar N, Wang Y, Gonzalez-Juarbe N, et al. Streptococcus pneumoniae in the heart subvert the host reponse through biofilmmediated resident macrophage killing. PLoS Pathog 2017; 13(8): e1006582.

98. Feldman C, Kallenbach JM, Levy H, Reinach SG, Hurwitz MD, Thorburn JR, et al. Community-acquired pneumonia of diverse aetiology: prognostic features in 
patients admitted to an intensive care unit and a "severity of illness" core. Intensive Care Med 1989; 15(5): 302-307.

99. Feldman C, Kallenbach JM, Levy H, Thorburn JR, Hurwitz MD, Koornhof HJ. Comparison of bacteraemic community-acquired lobar pneumonia due to Streptococcus pneumoniae and Klebsiella pneumoniae in an intensive care unit. Respiration 1991; 58(5-6): 265-270.

100. Brogly N, Devos P, Boussekey N, Georges H, Chiche A, Leroy O. Impact of thrombocytopenia on outcome of patients admitted to ICU for severe communityacquired pneumonia. J Infect 2007; 55(2): 136-140.

101. Claushuis TA, van Vught LA, Scicluna BP, Wiewel MA, Klein Klouwenberg PM, Hoogendijk AJ, et al. Thrombocytopenia is associated with a dysregulated host response in critically ill sepsis patients. Blood 2016; 127(24): 3062-3072.

102. Mirsaeidi M, Peyrani P, Aliberti S, Filardo G, Bordon J, Blasi F, et al. Thrombocytopenia and thrombocytosis at time of hospitalization predict mortality in patients with community-acquired pneumonia. Chest 2010; 137(2): 416-420.

103. Prina E, Ferrer M, Ranzani OT, Polverino E, Cillóniz C, Moreno E, et al. Thrombocytosis is a marker of poor outcome in community-acquired pneumonia. Chest 2013; 143(3): 767-775.

104. EIMaraghy AA, AbdelFattah EB, Ahmed MS. Platelet count: Is it a possible marker for severity and outcome of community acquired pneumonia? Egypt $J$ Chest Dis Tuberc 2016; 65(2): 499-504. Doi: 10.1016/j.ejcdt.2015.09.001.

105. Garin N, Felix G, Chuard C, Genné D, Carballo S, Hugli O, et al. Predictors and implications of early clinical stability in patients hospitalized for moderately severe community-acquired pneumonia. PLoS One 2016; 11(6): e0157350.

106. Garin N, Genné D, Carballo S, Chuard C, Eich G, Hugli O, et al. $\beta$-Lactam monotherapy vs $\beta$-lactam-macrolide combination treatment in moderately severe community-acquired pneumonia: a randomized noninferiority trial. JAMA Intern Med 2014; 174(12): 1894-1901.

107. Gorelik O, Izhakian S, Barchel D, Almoznino-Sarafian D, Tzur I, Swarka M, et al. Prognostic significance of platelet count changes during hospitalization for community-acquired pneumonia. Platelets 2017; 28(4): 380-386.

108. Kraakman MJ, Lee MK, AI-Sharea A, Dragoljevic D, Barrett TJ, Montenont E, et al. Neutrophil-derived $\mathrm{S} 100$ calcium-binding proteins A8/A9 promote 
reticulated thrombocytosis and atherogenesis in diabetes. J Clin Invest 2017; 127(6): 2133-2147.

109. Cangemi R, Pignatelli P, Carnevale R, Bartimoccia S, Nocella C, Falcone M, et al; Sixtus Study Group. Low-grade endotoxemia, gut permeability and platelet activation in community-acquired pneumonia. J Infect 2016; 73(2): 107-114.

110. Ferroni P, Riondino S, Vazzana N, Santoro N, Guadagni F, Davi G.

Biomarkers of platelet activation in acute coronary syndromes. Thromb Haemost 2012; 108(6): 1109-1123.

111. Tunjungputri RN, van de Heijden $W$, Urbanus $R T$, de Groot $P G$, van der Ven A, de Mast $Q$. Higher platelet reactivity and platelet-monocyte complex formation in Gram-positive sepsis compared to Gram-negative sepsis. Platelets 2016; doi: 10.1080/09537104.2016.1252837 [Epub ahead of print].

112. Wildhagen KC, Wiewel MA, Schultz MJ, Horn J, Schrijver R, Reutelingsperger $\mathrm{CP}$, et al. Extracellular histone $\mathrm{H} 3$ levels are inversely correlated with antithrombin levels and platelet counts and are associated with mortality in sepsis patients. Thromb Res 2015; 136(3): 542-547.

113. Lam FW, Cruz MA, Leung HC, Parikh KS, Smith CW, Rumbaut RE. Histone induced platelet aggregation is inhibited by normal albumin. Thromb Res 2013; 132(1): 69-76.

114. Zampetaki A, Willeit P, Tilling L, Drozdov I, Prokopi M, Renard JM, et al. Prospective study on circulating microRNAs and risk of myocardial infarction. $J$ Am Coll Cardiol 2012; 60(4): 290-299.

115. Kaudewitz D, Skroblin P, Bender LH, Barwari T, Willeit P, Pechlaner R, et al. Association of microRNAs and YRNAs with platelet function. Circ Res 2016; 118(3): 420-432.

116. Sunderland N, Skroblin P, Barwari T, Huntley R, Lu R, Joshi A, et al. MicroRNA biomarkers and platelet reactivity: the clot thickens. Circ Res 2017; 120(2): 418-435.

117. Powers ME, Becker RE, Sailer A, Turner JR, Bubeck Wardenburg J. Synergistic action of Staphylococcus aureus $\alpha$-toxin on platelets and myeloid lineage cells contributes to lethal sepsis. Cell Host Microbe 2015; 17(6): 775787. 
118. Ren F, Mu N, Zhang X, Tan J, Li L, Zhang C, et al. Increased plateletleukocyte aggregates are associated with myocardial no-reflow in patients with ST elevation myocardial infarction. Am J Med Sci 2016; 352(3): 261-266.

119. Reyes LF, Restrepo MI, Hinojosa CA, Soni NJ, Anzueto A, Babu BL, et al. Severe pneumococcal pneumonia causes acute cardiac toxicity and subsequent cardiac remodeling. Am J Respir Crit Care Med 2017; doi: 10.1164/rccm.201701$01040 C$ [Epub ahead of print]. 